\title{
Precarious or Decent Work? Perceived Working Conditions and Life Satisfaction of SME Workers in Sylhet, Bangladesh
}

\author{
A H M Belayeth Hussain, Ph.D. \\ Centre for Research on Women \& Gender (KANITA) \\ Universiti Sains Malaysia (USM) \\ Malaysia \\ Tel: +60 46533681 \\ Email: belayeth@usm.my \\ ORCID: https://orcid.org/0000-0002-9509-9562 \\ Noraida Endut, Ph.D. \\ Centre for Research on Women \& Gender (KANITA) \\ Universiti Sains Malaysia (USM) \\ Malaysia \\ Tel: +60 46532678 \\ Email: idaman@usm.my \\ Sumena Sultana \\ Department of Sociology \\ Shahjalal University of Science \& Technology \\ Bangladesh \\ Tel: +880 1717431701 \\ Email: sumena_sultana@yahoo.com
}




\begin{abstract}
This study measures key indicators of perceived precarity and decent working conditions and their relative effects on life satisfaction of workers in small and medium-sized enterprises. Using a random sample survey, we interviewed 103 workers in four districts of Sylhet division in Bangladesh. Utilizing Smart PLS application for structural equation modeling, we iterated the samples 1000 times which resulted in a new sample size standing at 499. We used a Likert-type five-point scaling technique, with appropriate items related to the latent constructs of the model, for path analysis. We found perceived precariousness has the highest causal relations with a path coefficient of 0.706 with social dialogue (an indicator of decent working conditions) followed by 0.539 with working hour issue, 0.345 with life satisfaction and 0.301 with the unacceptable work issue. The importanceperformance map analysis confirms that perceived precarity is the most critical construct for worker's life satisfaction. Thus, in a ceteris paribus situation, an increase of one point in the performance on the perceived precarity is expected to increase in the performance on the life satisfaction by a total effect level of 0.428 . Therefore, we recommend further attention should be paid by the policymakers to the issue of consciousness of the precarity at the workplace for a better life satisfaction of workers.
\end{abstract}

Keywords: Precarity, decent works, life satisfaction, SMEs, PLS-SEM. 
Poverty reduction and sustainable growth are the basic targets of the contemporary development agenda in Bangladesh, which is one of the countries with a plentiful labour supply. To achieve the development goals, the main strategy comprises with the creation of a more productive employment sector and transferring labour force from a low return agriculture-based economy to a structured manufacturing and service sector economy. It is often said that under proper conditions, the surplus labour has the potential to promote economic growth. However, to achieve a better outcome from this abundant labour supply, it requires increased labour efficiency and improved working conditions in the labour market.

Small and medium-sized enterprises (SMEs) play an essential role in the economic development of developing countries. There is agreement that a strong SME segment is one of the key strengths for the development of the Bangladesh economy, driving private ownership, creating jobs and stimulating diversified economic activity (Zaman and Islam 2011). The SMEs are generally seen as an important source of job creation. However, this source lacks a meaningful relation to policy formulations to avoid various risks in a working environment. The SMEs in the developing countries provide a broad employment base but are not adequate in terms of their working conditions (ILO 2015). It is therefore important to identify the strengths and weaknesses of small and mediumsized enterprises, especially in the political and decision-making process (Sarder 2010). Although a number of studies have pointed to operational limitations faced by entrepreneurs, the unbridled growth of the informal sector and its resultant working conditions have been ignored in academic research.

In 1999, the Directorate General of the International Labour Conference presented the concept of decent work to explain four of its pillars: employment, social security, labour rights, and social dialogue. Among them, employment encompasses all forms of work, and decent work is therefore relevant not only to workers in a formal economy but also to the informal sector, including the self-employed, unregulated wage earners and domestic workers (Ghai 2003). The concept of decent work integrates the fundamental and labour rights of workers (ILO 1999). Fundamental rights relate to freedom of association, equality of work and the absence of forced and child labour in any abusive form. Finally, the social dialogue includes workers' rights in consultations with employers on the occupational issues. Among many relevant decent work indicators, one of the most influential studies on decent work indicators was probably carried out by Anker et al. (2002) who identified eleven statistically measurable indicators of decent work. These indicators include the practice of decent working hours, the existence of unacceptable works, including child labour, and the practice of employment relations through social dialogue. Although there is ample literature on the working conditions of workers in various economic activities, the studies have been carried out in informal sectors and in particular in small and medium-sized enterprises (SMEs), which are vital elements of poverty reduction and regional inequality (GOB, 2011). Hussain and Endut (2018a, 2018b) have conducted their recent studies among SME workers, arguing that workplace relations through social dialogue have a significant impact on ensuring decent working conditions and work-life balance. The micro, small and medium-sized enterprises (MSMEs) employ 31 million people, which corresponds to 40 percent of the total population of Bangladesh in the age group 15 years and older (Rahman 2009). It is therefore timely issue to examine whether the perceived precariousness and decent working conditions affect the life satisfaction of workers in the informal sector, namely SMEs. In our current study, we consider these indicators as working 
constructs of our structural equation model (SEM), in which we try to investigate path relationships between constructs.

The Bangladesh Decent Work Country Programme (DWCP) for 2006-2009 includes three priorities, including decent and creative employment, rights at work and other ILO prescriptions, which are considered as the basic pillars in achieving a decent work environment (Mondal 2010). The progress in employment opportunities in the last two decades has been varied, especially in the areas of gender, youth, and informal employment sector. Therefore, the potential of entrepreneurship, creative productivity and the ethics of people in the informal economy must be recognized to address labour rights issues (Trebilcock 2005). The information gap and lack of sufficient data may weaken and challenge the advancing gains of the decent work paradigm. In many jobs where the working conditions are weak, social dialogue is poorly practised or livelihood is not sustainable; the idea of decent work is more challenging therein and precarity moves high. Many studies have identified the multi-causal problem behind the surplus labour force and suggested for new job creation (ADB, 2010). However, the existing crisis in the informal sector has always been untouched or partially ignored and needs to be addressed to receive proper avenue for further development. There is an irresistible need for sufficient employment opportunities to strengthen the economy through by achieving decent work and by reducing precarious works in a working place.

\section{Indicators of precarity}

The extensive use of precarious employment is not essentially new (Quinlan et al. 2001; Benanch et al. 2014; Kalleberg 2009), and could be found in insecure employment, small workshops, home-based work, selfemployment and other informal arrangements Quinlan et al. 2001). The term has been broadly used for decades in sociology, economics, and political science, and in the media (Vosko 2006; Kolleberg 2009). Various changes took place during the last three decades of the twentieth century and paved the way through which precarious forms of employment expanded globally and received academic attention in sociological research.

Although there is a little consensus on a working definition of precarity, several researchers put forward its definitions to a broader social environment where it is embedded in (Benanch et al. 2014; Benanch et al. 2016). According to them, precarious employment is a multidimensional construct that differs across countries and depending on the specific economic and social structure of the labour market (Benanch et al. 2016; Bosmans et al. 2016; Pacheaco et al. 2014 and Moscone et al. 2016). It is a non-standard work (Campbell 2010; Mantouvalou 2012; Lightman et al. 2008) and can be defined through using one single indicator- job insecurity (Brackpool and Neil 2017) or poor legislative protection of worker's rights (Mantouvalou 2012). However, the precariousness can also be a multidimensional phenomenon with more than one single latent construct and may comprise six factors: non-standard working hours, employment instability, collective voice, quality of work environment, duration of employment and part-time work (Pacheco et al. 2014). Although there are multiple indicators involved to define precariousness, the most important indicator seems to be the issue of limited workplace rights and social protection and powerlessness to exercise legally granted workplace rights with other relevant indicators such as employment insecurity, low wages, individualized bargaining relations and overall working environment (Benanch et al. 2016; Edralin 2014; Lewchak et al. 2003). Using the multidimensional Employment Precarious 
Scale, Vives et al. (2013) assessed precarious work more concretely covering a scale of 26 items that include job instability, individual-level bargaining power over wage and working hours, workplace rights and vulnerability.

In Asia, workers in the informal sector tend to be described as precarious. According to Reza (2016), the construction industry in Bangladesh is responsible for a considerable proportion of precarious workers. Other studies (Barkat et al. 2003; Agarwala 2014) argue garment work is considered precarious in the sense that employment contracts have limited social benefits and legal entitlements, job insecurity, low employment, low incomes, poor working conditions, and high health risks. As precarious work increases worldwide, researchers intend to examine the impact it has on workers' life satisfaction. At the same time, most researchers examine the relationship between precarious employment and health status and confirm that precarious employment is a social determinant affecting the physical and mental health of workers, their families, and communities (Vives et al. 2013; Lewchak et al. 2003; Benanch et al. 2014; Moscone et al. 2016). Our current study offers a new analysis that examines whether the perception of a number of indicators of precarious work affects the perception of decent work in the workplace of SMEs and thus affects employee satisfaction in SMEs (informal workers). This study shows the extent and nature of perceived precariousness and decent work and their impact on life satisfaction.

\section{Indicators of life satisfaction}

In their study, Diener et al. (1985) consider life satisfaction as a cognitive, judgmental process. Actually, judgments of satisfaction depend upon a comparison of one's circumstances with what is thought to be an appropriate standard. So, it is necessary to sketch out that the judgment of how satisfied people are with their present situation is based on a comparison with a standard which each individual sets for him or herself; it is not externally imposed (Diener 1984). That is why, Diener et al. (1985), in their study, based on three study groups, develop a Satisfaction with Life Scale (SWLS) to measure life satisfaction. It is a multi-item scale and is designed around the idea that one must ask respondents for a total judgment of their lives. The scale considers five statements (such as, "In most ways my life is close to my ideal", "The conditions of my life are excellent", "I am satisfied with my life", "So far I have gotten the important things I want in life", and "If I could live my life over, I would change almost nothing".) and the respondents must express their attitudes against each corresponding statement by using seven categories $(1=$ strongly disagree; $2=$ disagree, $3=$ slightly disagree; $4=$ neither agree nor disagree; $5=$ slightly agree; $6=$ agree, and $7=$ strongly agree). In their study, Diener et al. used the SWLS to measure life satisfaction of two samples of undergraduates and fifty-three elderly persons living in the UrbanaChampaign area and argue that unlike other scales, the SWLS leaves the respondents free to weight other domains (suppose health and material wealth) and various feeling states (e.g., loneliness) in whatever way he or she chooses.

Precarious work could have a negative impact on workers' life satisfaction. Therefore, psychology in the workplace is an important phenomenon that motivates and satisfies employees to perform well in the workplace (Murthy and Shastri 2015). This applies not only to organizational benefits but also to personal growth and development, such as self-confidence, crisis management and problem - solving strategies. Theoretically, WorkLife-Balance (WLB) practices give employees a sense of confidence that their organization/employer is supporting the well-being and non-work needs of employees. According to organizational support theory 
(Eisenberger et al. 1986) and the theory of social exchange, the feeling of support results in higher positive attitudes towards the organization and promotes employee participation and initiative through a felt obligation to offer additional benefits in return (Lambert 2000). For instance, flexible working hours have shown less absenteeism and increased job satisfaction (Baltes et al. 1999). Workers friendly interventions are usually referred to as family-friendly policies or work-life benefits and policies (Osterman 1995).

\section{Materials and methods}

Data

Using a survey method, this study has collected data from 103 respondents who work at small and medium-sized enterprises that are SME credit recipients of different banks of Sylhet division in Bangladesh. We selected them to use a randomly chosen list of loan receivers who were administered by Bangladesh Bank (State bank of Bangladesh). This list has been prepared by Bangladesh Bank for their monthly mobile inspection over the enterprises. The operating SMEs receive their loans through their relevant scheduled and private banks. The interviewed respondents work at respective SMEs in different districts of Sylhet division- Sylhet, Moulvibazar, Habiganj, and Sunamganj. We considered enlisted credit recipient SMEs as the population of the present study and interviewed one worker from each selected SME. Until October 2017, the total number of 9,268 SMEs received loans from various public and private banks in Sylhet division. As we mentioned, by employing a survey method, 103 workers have been interviewed. In the SmartPLS application, we used the iteration technique, which was set to 1000 times and therefore, the new sample stood at 499. When we use the partial list square-structural equation modelling (PLS-SEM), the minimum sample size considerations should be (whichever is the larger) based on either condition: a) ten times the largest number of formative indicators used to measure one latent construct; or, b) ten times the highest number of structural paths (arrow indicating) directed at a specific latent construct in a model (Hair et al. 2012). We have six indicators used to measure precarious works and the highest number of structural paths to satisfaction with life scale are four. Therefore, as per the rule of thumb of determining minimum sample size for PLS-SEM, we considered six indicators to measure precarious works. For this study, the minimum sample size was set to 60 . However, as we followed the random sampling of the inspection list of the year 2016-2017 from the Bangladesh Bank (State Bank of Bangladesh), we interviewed 103 respondents from 103 SMEs.

\section{Model}

This paper does not have the intention to test, confirm or compare theories; rather, the goal of this study is to predict some key target constructs and identify key driver constructs in analyzing indicators of precarious works, decent works, and life satisfaction. Therefore, we utilized PLS-SEM over covariance-based SEM (CB-SEM). To identify the significant associations between the perceived precarity, decent work, and life satisfaction, we modelled our study using the partial least square (PLS) structural equation modelling (SEM) technique. We utilized PLS-SEM path modelling to explore parsimonious path coefficients with significant effects of workers' perceived precarity on perceived decent work conditions and life satisfaction. Path models are diagrams used to display hypothetical and variable relationships in a structural equation model (Hair, et al. 2014). For ease of 
understanding, we demonstrated (Figure 2) constructs that have been used to explain the magnitude and significance of relationships among them (Please refer to the Table 1 for outer model legends).

Each construct has its relevant indicators, which have been measured directly. However, in our model, constructs are in latent form, and therefore, they must be measured indirectly. In our working model, we have a number of indicators inserted into a SmartPLS application (Ringle et al. 2015). In Table 1, we presented model constructs with their corresponding items, and a five-point Liker scale has been introduced to the respondents. When we surveyed our respondents, we collected data on the items used for scaling by 1 to 5 points. The constructs in the table were formed by referring to the statistical indicators of precarious works (based on existing literature), decent works (Anker et al. 2003) and satisfaction with life scale (Diener et al. 1985). To test our hypotheses, we used our model demonstrated in Figure 2. In this model, we used four endogenous constructs - social dialogue (SD), unacceptable work (UW), working hour (WH) and satisfaction with life scale (SWLS) and four exogenous constructs - social dialogue (SD), unacceptable work (UW), working hour (WH) and precarious work (PW). In our study, target constructs are - decent working condition and satisfaction with life. The decent working condition has been defined by three constructs- social dialogue (SD), unacceptable work (UW) and working hour (WH). On the other, we considered five indicators (based on Diener et al. 1985) for satisfaction with life scale (SWLS) which has been mentioned earlier and six indicators for precarity - salary, work contract, job security, safe work, injury insurance, and social-economic support to the family.

\section{Variables}

Statistical indicators of decent work (Anker et al. 2002) include employment opportunities, unacceptable work, adequate earning and productive work, decent hours, stability and security of work, combining work and family life, fair treatment in employment, safe work environment, social protection, social dialogue and workplace relations, economic and social context of decent work. Our present study principally focuses on three statistical indicators such as social dialogue, unacceptable work and decent working hour in searching for parsimonious path coefficients between perceived precarity, decent working conditions and life satisfaction as mentioned earlier. We defined precarious work as a multidimensional phenomenon (Pacheco et al. 2014) depending on nonstandard working hours, employment instability, the absence of collective voice, shortage of quality of work environment, duration of employment and part-time works. In our model, we also have a dependent constructsatisfaction with life scale. We defined this variable as per the study conducted by Diener et al. (1985) who considered life satisfaction as a cognitive and judgmental process. All latent variables used in our present study are shown in Table 1 which demonstrates all items used in a five-point Liker type scale. Considering our working variables and their corresponding path model, we assume two hypotheses for this study:

H1: Workers' perceived decent working conditions depend on perceived precarity.

$\mathrm{H} 2$ : Workers' perceived precarity affects their life satisfaction. 


\section{Quality criteria of the measurement model}

Before going into the hypotheses tests and interpretations, in PLS-SEM, a model requires its quality criteria assessment process that involves two stages according to Hair et al. (2014): before proceeding to evaluating a structural model, each reflective model must pass measurement model evaluation with satisfactory results. For our reflective model, we evaluate the measurement model with quality criteria. In this present study, we used two types of assessment processes that involve the internal consistency reliability of constructs and the discriminant validity of constructs.

For evaluating internal consistency reliability, we prefer to use composite reliability over Cronbach's Alpha. According to Hair et al. (2014), Chronbach's Alpha gives us an estimate of reliability based on inter-correlations of the observed indicator variables, but PLS-SEM prioritizes indicators according to their individual reliability. Moreover, Chronbach's Alpha is sensitive to the number of items in the scale and therefore underestimates the internal consistency reliability (Hair et al. 2014). A composite reliability score has the range of values from 0 to 1 where values above 0.70 are considered acceptable for a study (Hair et al. 2014; Sarstedt et al. 2014). In Table

2 , we see that the values for all constructs in the model qualify the satisfactory range.

To assess the discriminant validity of constructs in the model, we used the Heterotrait-Monotrait (HTMT) criterion rather than the Fornell-Larcker criterion. According to Henseler et al. (2015), the classical approaches (i.e., the Fornell-Larcker criterion and cross-loadings) do not reliably detect a lack of discriminant validity in common research situations. Therefore, they propose HTMT as an alternative approach to assessing discriminant validity. If we see the HTMT value standing below 0.90 (although there are some researchers who consider 0.85 as a threshold value), we conclude that the discriminant validity has been established between two reflective constructs (Henseler et al. 2015).

In our present model, we see that the constructs (except social dialogue to working hour with a little higher than 0.90 with the value 0.935 ) have the value of less than 0.90 of HTMT (Table 3). Therefore, we confirm that the discriminant validity of the model with very little difference for one association (social dialogue to working hour) has been established. In addition, we run HTMT inference criteria to decide on the significance of HTMT values. We look at the confidence intervals of all HTMT values of constructs in Table 3 and find that the upper confidence interval is below 1. Therefore, we conclude that all HTMT values differ significantly from 1 and thus the discriminant validity of the model has been established for the constructs involved in the model.

\section{Quality criteria of the structural model}

Before proceeding to measure the coefficients of determination $\left(\mathrm{R}^{2}\right)$ and path coefficients of the model, we must assess collinearity among the predictor constructs (Sarstedt et al. 2014). In the SmartPLS application, we use our model constructs to discover any potential collinearity issues among the predictor constructs. We find that all inner Variance Inflation Factor (VIF) values are well below 5.00 (lowest value is 1.00, and the highest value is 2.681). In a structural equation modelling, a VIF statistic measures the increase in the variance of an estimated regression coefficient when predictor constructs are correlated. A VIF value between 5 and 10 indicates that two constructs are highly correlated and therefore, may be problematic for the model prediction (blog.minitab.com, 
2015). We find in Table 5 that the highest VIF value is 2.681 , indicating that the predictors may be in a very little association, but this is not problematic for the model.

Since our working model is a reflective model, we only must consider the inner model VIF values of the collinearity statistic. According to Hair et al. (2014), the threshold value for VIF is 5. Because, in our model, the values of the inner model VIF fall below 5, we confirm that collinearity does not reach a critical level in any of our constructs, and therefore, it is not an issue for the estimation of the path model.

\section{State of precarity, decent work conditions, and life satisfaction}

Before exploring the interrelationships among the constructs in the model, we discuss different mean scores of each indicator. Table 1 refers to the scale (strongly agree $=5$, strongly disagree $=1$ ) constructs and their relevant indicators. We see that the construct unacceptable work (one indicator of decent working conditions) has the highest mean composite score (4.28) followed by social dialogue (3.66), precarious work (3.33) and working hour (3.08). Therefore, the workers engaged in the SMEs have more perceived knowledge about decent working conditions than precarious work. Some studies (Hussain and Endut 2018a; Volk and Hadler 2018) argue that the components of social dialogue have the highest impact on achieving decent working condition and work-life balance for the workers. However, this study explores that the indicator of unacceptable work has the largest share in decent work condition. To understand the interplay of the scale items within the indicators, we see that the workers' perceived safe work environment is the most important (mean score $=4.02$ ) issue among five items in the scale of precarious work. In response to a question - "sufficient salary is the most important thing to my work", the workers give a poorer score to this question than other including occupational injury insurance (3.58), job security (3.56) and job contract (3.17). On the other, it is obvious that the workers cannot find a work-life balance situation with their current job as we see the lowest score (2.75) that has been assigned to the question"with this job, I am able to support my family in economic and social terms".

In our study, social dialogue consists of the questions regarding unionism, workplace rights, and worker-employer relations. Overall, we find that SME workers' perceived knowledge about social dialogue receives above average composite score (mean composite score $=3.66$ ). Work right violation and unionism have the highest mean scores (3.81 and 3.80) among the five items. When we asked the respondents about their perception of working hour, they showed their position with neither agree nor disagree (mean composite score $=3.08$ ). This explains that SME workers have better-perceived knowledge of social dialogue than working hour. Although they understand the overtime and extra wages (3.72), yet they score poor about the working schedule (3.04 and 2.61) and flexibility (2.91). Among the three decent work indicators (social dialogue, working hour and unacceptable work) that have been used in this study, the workers have the highest average composite score (4.28) for unacceptable work. This implies that workers have a better understanding of nature and the consequences of unacceptable work in the workplace. It questions regarding child labour and hazardous works have been included in an unacceptable work indicator.

As we mentioned earlier that satisfaction with life scale (Diener et al. 1985) has been employed to explore workers' life satisfaction. Overall, workers have the mean life satisfaction composite score of 2.63 which discovers a very 
poor satisfaction level. The highest score to the question- "I am satisfied with my life" receives only 2.96 which shows neither agreement nor disagreement with the statement. The lowest mean score is 2.10 which has been assigned to the question "If I could live my life over, I would change almost nothing". The workers were found almost disagreed with that question. This means the workers are not satisfied with their current job.

\section{How important are precarity and decent work conditions to life satisfaction?}

After running the PLS-SEM algorithm for the model, we found the path coefficients (demonstrated in Figure 2) that estimate the structural model relationships. In the diagram, we found some very strong causal linkages among the constructs used in this model. It is clearly demonstrated that the perceived precariousness has the highest causal relations with a path coefficient of 0.706 with social dialogue (an indicator of decent working conditions) followed by 0.539 with working hour, 0.345 with satisfaction with life and 0.301 with unacceptable work. The significance of the model coefficients depends on their corresponding t-value that stands above 1.96. Therefore, we concluded that all path coefficients above 1.96 are significant to the $95 \%$ confidence level.

The most common measurement used to assess a structural model is the coefficient of determination $\left(\mathrm{R}^{2}\right)$ which measures the model's accuracy and predictive capacity (Hair et al. 2014). In our model, we see in the diagram (Figure 2) that the coefficient $\left(\mathrm{R}^{2}\right)$ represents the exogenous constructs' (PW, SD, UW, WH) combined effects on the endogenous latent constructs (SD, UW, WH, SWLS). The $\mathrm{R}^{2}$ value ranges from 0 to 1 (where 0.20 is considered high in a discipline related to consumer behaviour, also in behavioural sciences) with higher values indicating a better level of predictive accuracy (Hair et al. 2014). In this model, we see that the endogenous construct social dialogue (SD) has the $\mathrm{R}^{2}$ value of 0.498 followed 0.493 for working hour (WH), 0.277 for unacceptable work (UW) and 0.246 for satisfaction with life scale (SWLS) by which it is indicated that relevant exogenous constructs of the model explained $49.8 \%, 49.3 \%, 27.7 \%$ and $24.6 \%$ of the variance of the endogenous constructs SD, WH, UW, and SWLS respectively. Since the value is above the threshold level of 0.20 , we can confirm that the endogenous constructs can be explained well by the connected predictor constructs in the model.

In addition to assessing the $\mathrm{R}^{2}$ values of all endogenous constructs in the model, we must see whether any substantive change to the endogenous constructs occurs (we concentrate on SD, UW, WH, and SWLS) when we omit an exogenous construct from the model. For this purpose, we utilized effect size estimation $\left(\mathrm{f}^{2}\right)$, with assessment guideline values of 0.02, 0.15 and 0.35, representing small, medium and large effects of an exogenous construct on an endogenous construct of the model (Hair et al. 2014). In the model, we see that the effect size ( $\left.f^{2}\right)$ of exogenous construct precarious work (PW) to social dialogue (SD) is 0.993 followed by 0.288 for social dialogue (SD) to working hour (WH). Therefore, we infer that the exogenous constructs precarious work (PW) and social dialogue (SD) have significant effects on the model. Also, we see in Table 5 that other exogenous constructs have an insignificant effect on their respective endogenous constructs.

If we consider total and indirect specific effects of the constructs (Table 4), we see that the perceived of precarious work has the highest effects on perceived social dialogue, unacceptable work and working hour. These three constructs, in our study, have been defined as the conditions of decent works. The perceived precarious work also has a considerably high effect on the life satisfaction, when we consider the total effects. However, if we consider 
the indirect specific effects, we see that the perceptions of precarious work have insignificant effects on life satisfaction. Therefore, it is inferred that perceived precarious work has more effects on the perceived decent working conditions than life satisfaction. Although the total effect of the perceptions of precarious work to the life satisfaction is 0.428 , the all indirect effects (through decent working conditions) are found insignificant.

Social dialogue is recognized as the most important indicator for decent working conditions (Hussain and Endut 2018a) and for work-life balance (Hussain and Endut 2018b) situation, which is the major precondition for ensuring the better working conditions. It can confirm, for the employees in any organization, greater life satisfaction (Carlson and Kacmar 2000; Kim and Ling 2001; Hyman et al. 2003), improved working relations (Kossek and Ozeki 1998), least tension (Ezra and Deckman 1996), psychological well-being (Major et al. 2002), physical health (Frone et al. 1997; Kinnunen and Mauno 1998) and even marital satisfaction (Hughes and Parkes 2007). As a precondition of decent working conditions, social dialogue plays a great role and consists of the importance of trade union and its functionalities. Among some other factors, weak labour unionism, directly and indirectly, affects working conditions and hence affects people's well-being and life satisfaction (Benach et al. 1979 and Kalleberg 2009). In a recent multi-country study (Volk and Hadler 2018), it is found that 70\% of the respondents consider the trade union as necessary to protect their interests. However, in the same study, it was also found that overall $21 \%$ respondents think that it is bad for the economy considering India where $51 \%$ respondents see trade unions as bad for country's economy. Additionally, work-related distress (Yu 2013), wage, working hours (Medagyesi Zlyomi 2016) and working schedule and leave provisions (Makabe et al. 2015), all affect worker's job satisfaction and quality of life.

Perceptions of precarious work have direct and indirect effects on the life satisfaction. As we have seen in this study, perceived precarity has a more direct impact on life satisfaction than indirect impacts. Many studies revealed that employment stability and job security have a positive impact on the quality of life and life satisfaction (Scherer 2009; Fantone 2007; Cuyper et al. 2010; Khattab and Fenton 2009). In our study, a non-standard job in terms of employment stability has been set as a major indicator of precarious works.

\section{Importance and performance of indicators}

The Importance Performance Map Analysis (IPMA) is a useful technique in a structural equation model that informs us about the relative importance of constructs in explaining other participating constructs (Hair et al. 2014). With this technique, we can conclude the relative importance and performance of a construct toward its targeting construct. This may enable us to recommend further improvements in the performance of a construct that is of great importance in the inner and out models.

In the IPMA picture (Picture 1), we see that the construct precarious work (PW) has the highest importance for our target construct satisfaction with life (SWLS) with a value of 0.428 . At the same time, this construct has a very good performance (62.192\%) for the SWLS. By comparison, social dialogue (SD) has a better performance $(66.526 \%)$ for SWLS but has a very poor (-0.032) importance to the model. However, unacceptable work (UW) has a very good performance $(82.033 \%)$ and has a moderate importance $(0.239)$ in the model. In a ceteris paribus situation, considering our model, an increase of one point in the performance of the perceived precarious work 
(PW) is expected to increase the performance of life satisfaction (SWLS) by a total effect level of 0.428. Therefore, the perceptions about precarious work have a great importance and performance in explaining satisfaction with life of a worker.

\section{Conclusions}

The aim of this study was to explore the effects of perceived precarity on perceived decent working conditions and overall life satisfaction of the workers in small and medium-sized enterprises in Sylhet, Bangladesh. The results show that the perceived precarious work has the highest influence on the perceived social dialogue considered as one of the three constructs of decent works. At the same time, perceived precarity has also a significant direct influence on the life satisfaction. However, when we consider indirect specific effects, we see that perceived precarity has an insignificant effect on workers' life satisfaction. In our model, we also see that the indicator perceived unacceptable work has a very good impact on a worker's life satisfaction. A worker's life satisfaction depends substantially on the perceptions of precarity and perceptions of decent working conditions.

The importance-performance map analysis (IPMA) displays that the perceived precariousness has the highest importance in the model with a very high performance. We infer that in a condition where other constructs of the model remain constant, performing the satisfaction with life of a worker can be increased if there is an increase in the performance of the knowledge of precarious working conditions. Therefore, we recommend further attention should be paid by the policymakers to raising the consciousness of the precariousness at the workplace for a better satisfaction with life of workers. 


\section{References:}

ADB. (2010). The informal sector and informal employment in Bangladesh. Country Report 2010. Asian Development Bank: Manila. https://www.adb.org/sites/default/files/publication/30084/informal-sector-informalemployment-bangladesh.pdf. Accessed 14 October 2016.

Agarwala, R. (2014). Informal Workers' Struggles in Eight Countries. Brown Journal of World Affairs, XX(2), 251- 263.

Anker, R., Chernyshev, Egger, P., Mehran, F., \& Ritter, J. (2003). Measuring decent work with statistical indicators. International Labour Review, https://doi.org/10.1111/j.1564-913X.2003.tb00257.x

Anker, R., Chernyshev, I., Egger, P., Mehran, F. \& Ritter, J. (2002). Measuring decent work with statistical indicators. working paper no.2, policy integration department, statistical development and analysis group. Geneva: ILO.

Baltes, B. B., Briggs, T. E., Huff, J. W., Wright, J. A., \& Neuman, G. A. (1999). Flexible and compressed workweek schedules: A meta-analysis of their effects on work-related criteria. Journal of Applied Psychology, $84,496-513$

Barkat, A., Ahmed, S.N., Maksud, A.K.M. \& Ali, M.A. (2003). The cost for women workers of precarious employment in Bangladesh. Research Paper in Women in Informal Employment: Globalizing and Organizing (WIEGO), Human Development Research Centre, Oxfam GB.

Benach, J., Amble, M., Muntaner, C. \& Benavides, F. G. (1979). The consequences of flexible work for health: Are we looking at the right place?. Journal of Epidemiology and community health, 56(6).

Benach, J., Vives, A., Amable, M., Vanroelen, C., Tarafa, G. \& Muntaner, C. (2014). Precarious employment: understanding an emerging social determinant of health. Annual Review of Public Health, https://doi.org/10.1146/annurev-publhealth-032013-182500

Benach, J., Vives, A., Tarafa, G., Delclos, C. \& Muntaner, C. (2016). What should we know about precarious employment and health in 2025? Framing the agenda for the next decade of research. International Journal of Epidemiology, https://doi.org/10.1093/ije/dyv342

Brackpool, J. and Neil, L. (2017). Employment within the NCAA: precarious working conditions of student-athletes. Laurier Undergraduate Journal of Arts, 3(1), 1-24.

Campbell, I. (2010). The rise in precarious employment and union responses in Australia. In Carole Thornley, Steve Jefferys and Beatrice Appay (ed.), Globalization and Precarious Forms of Production and Employment: Challenges for Workers and Unions (pp. 114-132). Cheltenham UK: Edward Elgar.

Carlson, D. S., \& Kacmar, K. M. (2000). Work-family conflict in the organization: Do life role values make a difference?. Journal of Management, 26(5), 1031-1054.

Cuyper, N. D., Witte, H. D., Kinnunen, U. \& Natti, J. (2010). The Relationship Between Job Insecurity and Employability and Well-Being Among Finnish Temporary and Permanent Employees. International Studies of Management \& Organization, https://doi.org/10.2753/IMO0020-8825400104

Diener, E. (1984). Subjective well-being. Psychological Bulletin, 95, 542-575.

Diener, E., Emmons, R.A., Larsen, R.J., Griffin, S. (1985). The satisfaction with life scale. Journal of Personality Assessment, 49, 71-75.

Edralin, D. M. (2014). Precarious work undermines decent work: the unionized hotels workers' experiences. DLSU Business and Economics Review, 24(1), 13-26.

Eisenberger, R., Huntington, R., Hutchison, S., \& Sowa, D. (1986). Perceived organizational support. Journal of Applied Psychology, 71, $500-507$.

Ezra, M. \& Deckman, M. (1996). Balancing Work and Family Responsibilities: Flextime and Child Care in the Federal Government. Public \& Administration \& Review, 56(2), 174-9.

Fantone, L. (2007). Precarious Changes: Gender and Generational Politics in Contemporary Italy. Feminist Review, (87), 5-20. http://www.jstor.org/stable/30140797. Accessed 5 December 2016.

Frone, M. R., Yardley, J. K., \& Markel, K. S. (1997). Developing and testing an integrative model of the work family interface. Journal of Vocational Behavior, 50, 145-167. 
Ghai, D. (2003). Decent work: Concept and Indicators. International Labour Review, 142 (2), 114-145.

GOB (2011). 6th Five Year Plan. General Economic Division. Planning Commission, Dhaka.

Hair, J. F., Sarstedt, M., Ringle, C. M. et al. (2012). An assessment of the use of partial least squares structural equation modeling in marketing research. Journal of the Academy of Marketing Science. https://doi.org/10.1007/s11747-011-0261-6

Hair, Jr. J. F., Hult, G. T. M., Ringle, C., \& Sarstedt, M. (2014). A primer on partial least squares structural equation modeling (PLS-SEM). Thousand Oaks: Sage Publications.

Hannah, V. \& Markus, H. (2018). Work Orientations and Perceived Working Conditions across Countries: Results from the 2015 ISSP Survey. International Journal of Sociology, https://doi.org/10.1080/00207659.2018.1446116

Henseler, J., Ringle, C. M., \& Sarstedt, M. (2015). A new criterion for assessing discriminant validity in variancebased structural equation modeling. Journal of the Academy of Marketing Science, https://doi.org/10.1007/s11747-014-0403-8

Hughes, E. L., \& Parkes, K. R. (2007). Work hours and wellbeing: The roles of work-time control and workfamily interference. Work and Stress, 21, 264-278.

Hussain, A.H.M.B., \& Endut, N. (2018a) Factors influencing working conditions of small enterprises in Sylhet City, Bangladesh. Development in Practice, https://doi.org/10.1080/09614524.2018.1404008

Hussain, A.H.M.B., \& Endut, N. (2018b). Do decent working conditions contribute to work-life balance: A study of small enterprises in Bangladesh. Asia Pacific Journal of Innovation and Entrepreneurship, https://doi.org/10.1080/09614524.2018.1404008

Hyman, J., Baldry, C., Scholarios, D. \& Bunzel, D. (2003). Work-life imbalance in the new service sector economy. British Journal of Industrial Relations, 41, 215-39.

ILO (1999). International Labour Conference. 87 $7^{\text {th }}$ Session, 1-17 June, 1999. http://www.ilo.org/public/libdoc/ILO_Chronology/09616(1999-87)Somavia.pdf. Accessed 20 November 2015.

ILO (2015) Small and medium sized enterprises and decent and productive employment creation. Geneva: Report $04,104^{\text {th }}$ session.

Kalleberg, A. L. (2009). Precarious work. Insecure workers: employment relations in transition. American Sociological Review, https://doi.org/10.1177\%2F000312240907400101

Khattab, N. \& Fenton, S. (2009). What makes young adults happy? Employment and non-work as determinants of life satisfaction. Sociology, https://doi.org/10.1177\%2F0038038508099095

Kim, S. L. F., \& Ling, S. C. (2001). Work-Family conflict of women entrepreneurs in Singapore. Women in Management Review, 16(5), 204-221.

Kinnunen, U. \& Mauno, S. (1998). Antecedents and outcomes of work-family conflict among employed women and men in Finland. Human Relations, 51, $157-177$.

Kossek, E. E., \& Ozeki, C. (1998). Work family conflict, policies, and the job life satisfaction relationship: A review and directions for organizational behavior-human resources research. Journal of Applied Psychology, 83(2), 139-149.

Lambert, S. J. (2000). Added benefits: The link between work-life benefits and organizational citizenship behavior. Academy of Management Journal, 43(5), 801-815.

Lewchak, W., de Wolff, A., King, A. \& Polanyi, M. (2003). From job strain to employment strain: health effects of precarious employment, Just Labour, 3, 23-35.

Lightman, E. S., Mitchell, A. \& Herd, D. (2008). Globalization, precarious work, and the food bank. The Journal of Sociology and Social Welfare, 35(2), 9-28.

Major, V. S., Klein, K. J., \& Ehrhart, M. G. (2002). Work time, work interference with family, and psychological distress. Journal of Applied Psychology, 87(3), 427-436.

Makabe, S., Takagai, J., Asanuma, Y., Ohtomo, K. \& Kimura, Y. (2015). Impact of work-life imbalance on job satisfaction and quality of life among hospital nurses in Japan. Industrial Health, https://doi.org/10.2486/indhealth.2014-0141 
Mantouvalou, V. (2012). Human rights for precarious workers: the legislative precariousness of domestic labour. UCL Labour Rights Institute online Working Papers, 2, 1-24. http://www.kalayaan.org.uk/wpcontent/uploads/2014/09/Mantouvalou DomesticWorkers.pdf. Accessed 27 November 2016.

Medgyesi, M. \& Zolymi, E. (2016). Job satisfaction and satisfaction in financial situation and their impact on life satisfaction. European Commission, Directorate general for employment, social affairs and inclusion, 6. Retrieved from

Mondal, A. H. (2010). Monitoring and assessing progress on decent work in Bangladesh. Dhaka and Geneva: ILO.

Moscone, F., Tosetti, E. and Vittadini, G. (2016). The impact of precarious employment on mental health: the case of Italy. Social Science \& Medicine, https://doi.org/10.1016/j.socscimed.2016.03.008

Murthy, N. M., \& Shastri, S. (2015). A Qualitative Study on Work Life Balance of Employees Working in Private Sector. International Journal of Recent Scientific Research, 6 (7), 5160-5167.

Osterman, P. (1995). Work family programs and the employment relationship. Administrative Science Quarterly, 40(4), 681-700.

Pacheco, G., Morrison, P. S., Cochrane, B., Blumenfeld, S. \& Rosenberg, B. (2014). Understanding Insecure Work, Centre for Labour, Employment and Work. Work Research Institute, New Zealand. https://workresearch.aut.ac.nz/ data/assets/pdf file/0019/56224/Understanding-Insecure-Workbrochure.pdf. Accessed 10 November 2016.

Quinlan, M. (2001). The global expansion of precarious employment, work disorganization and occupational health: a review of recent research. International Journal of Health Services, https://doi.org/10.2190\%2F607H-TTV0-QCN6-YLT4

Rahman, A. (2009), "Ideal financial solution for SMEs”, The Financial Express, July 26, Dhaka.

Reza, S. (2016). Hyper-individualized recruitment: rural-urban labour migration and precarious construction work in Bangladesh. Migration, Mobility and Displacement, 2(2), 41-61.

Ringle, Christian M., Wende, Sven, \& Becker, Jan-Michael (2015) SmartPLS 3. Bönningstedt: SmartPLS. http://www.smartpls.com. Accessed 20 November 2016.

Sarder J. (2010). An assessment of operational conditions of cottage, small medium enterprises (CSME) in Bangladesh. Report for FBCCI, Dhaka.

Sarstedt, M., Ringle, C. M. Henseler, J. \& Hair, J. F. (2014). On the Emancipation of PLS-SEM: A Commentary on Rigdon (2012). Long Range Planning, https://doi.org/10.1016/j.1rp.2014.02.007

Scherer, S. (2009). The social consequences of insecure jobs. Social indicators Research, https://doi.org/10.1007/s11205-008-9431-4

Trebilcock, A. (2005) Decent Work and the Informal Economy. Discussion Paper 2005/004. Helsinki: UNU-WIDER. https://www.wider.unu.edu/publication/decent-work-and-informal-economy. Accessed 12 December 2016.

Vives, A., Amable, M., Ferrer, M., Moncada, S., Llorens, C., Muntaner, C., Benavides, F.G.\& Benach, J. (2013). Employment precariousness and poor mental health: evidence from Spain on a new social determinant of health. Journal of Environmental and Mental Health, 2013, 1-10.

Vosko, L. F. (2006). Precarious Employment: Towards an improved understanding of labour market insecurity, 1st ed., McGill-queens University Press, 3-39.

Yu, Wei-hsin. (2013). It's who you work with: effects of workplace shares of nonstandard employees and women in Japan. Social Forces, https://doi.org/10.1093/sf/sot075

Zaman, Uz \& Islam M. J. (2011). Small and medium enterprises development in Bangladesh: problems and prospects, ASA University Review, 5(1), 145-160. 


\section{Tables:}

Table 1.

Constructs' scale and their relevant items

(Strongly agree $=5$, strongly disagree $=1$ )

\section{Precarious Work}

A1. Sufficient salary is the most important thing to my work

Mean score

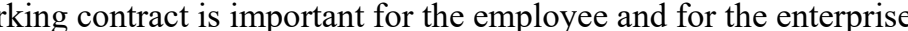

A3. A worker's job security is crucial for the employee and for the enterprise

A4. A safe working environment is a necessary condition or the worker

A5. Occupational injury insurance can protect a worker's good health

A6. With this job, I am able to support my family in economic and social terms

C1. Unionism is an important issue for the worker and for the enterprise

C2. Being a member of a union/association is a crucial issue for SME development

C3. I can raise my voice when I see any violation of work right at my workplace

C4. Allowing employees in decision-making process is important for the enterprise

C5. Employees should be free to abstain from their work voluntarily

B1. Working hours should be less than eight hours a day

B2. I can change my working time flexibly whenever I need

B3. Working time should not be during evening/night

B4. Working time should not be during holidays

B5. Working time which exceeds eight hours should be considered as overtime and be paid extra wages

\section{Unacceptable Work}

D1. Workers must not appear in dangerous works

D2. Children must not be allowed in the workplace

D3. Children should go to school rather than attending works

Satisfaction with Life

E1. In most ways, my life is close to my ideals

E2. The conditions of my life are excellent

E3. I am satisfied with my life

E4. So far, I have gotten the important things in my life

Table 2.

Composite reliability and $R^{2}$ of the model

\begin{tabular}{|l|c|c|}
\hline Construct & Composite reliability & $R^{2}$ \\
\hline Precarious Works (PW) & 0.832 & --- \\
\hline Social Dialogue (SD) & 0.816 & 0.498 \\
\hline Satisfaction with Life Scale (SWLS) & 0.922 & 0.246 \\
\hline Unacceptable Works (UW) & 0.818 & 0.277 \\
\hline Working Hours (WH) & 0.700 & 0.493 \\
\hline
\end{tabular}


Table 3.

Discriminant validity of constructs (HTMT ration)

\begin{tabular}{|l|c|c|c|}
\hline Constructs & HTMT & T Statistics & P Values \\
\hline Social Dialogue -> Precarious Works & 0.877 & 13.607 & 0.000 \\
\hline Satisfaction with Life Scale -> Precarious Works & 0.557 & 8.291 & 0.000 \\
\hline Satisfaction with Life Scale -> Social Dialogue & 0.337 & 4.354 & 0.000 \\
\hline Unacceptable Works -> Precarious Works & 0.582 & 8.092 & 0.000 \\
\hline Unacceptable Works -> Social Dialogue & 0.631 & 6.969 & 0.000 \\
\hline Unacceptable Works -> Satisfaction with Life Scale & 0.416 & 4.797 & 0.000 \\
\hline Working Hours -> Precarious Works & 0.734 & 8.976 & 0.000 \\
\hline Working Hours -> Social Dialogue & 0.935 & 9.583 & 0.000 \\
\hline Working Hours -> Satisfaction with Life Scale & 0.401 & 5.104 & 0.000 \\
\hline Working Hours -> Unacceptable Works & 0.461 & 5.309 & 0.000 \\
\hline
\end{tabular}

Table 4.

Path coefficients, total effects and total indirect effects (with $p$ values)

\begin{tabular}{|l|c|c|c|}
\hline Constructs & $\begin{array}{c}\text { Path coefficient } \\
(\mathrm{p} \text { values })\end{array}$ & $\begin{array}{c}\text { Total effects } \\
(\mathrm{p} \text { values })\end{array}$ & $\begin{array}{c}\text { Total indirect } \\
\text { effects }(\mathrm{p} \text { values })\end{array}$ \\
\hline Precarious Works -> Social Dialogue & $0.706(0.000)$ & $0.706(0.000)$ & --- \\
\hline Precarious Works -> Satisfaction with Life Scale & $0.345(0.002)$ & $0.428(0.000)$ & $0.083(0.171)$ \\
\hline Social Dialogue -> Satisfaction with Life Scale & $-0.212(0.060)$ & $-0.032(0.388)$ & $0.179(0.016)$ \\
\hline Precarious Works -> Unacceptable Works & $0.268(0.003)$ & $0.481(0.000)$ & $0.213(0.005)$ \\
\hline Social Dialogue -> Unacceptable Works & $0.301(0.004)$ & $0.301(0.004)$ & ---- \\
\hline Unacceptable Works -> Satisfaction with Life Scale & $0.239(0.020)$ & $0.239(0.020)$ & ---- \\
\hline Precarious Works -> Working Hours & $0.208(0.027)$ & $0.589(0.000)$ & $0.381(0.000)$ \\
\hline Social Dialogue -> Working Hours & $0.539(0.000)$ & $0.539(0.000)$ & ---- \\
\hline Working Hours -> Satisfaction with Life Scale & $0.199(0.063)$ & $0.199(0.063)$ & ---- \\
\hline
\end{tabular}

Table 5.

Effect size (first row) and inner VIF (second row) values

\begin{tabular}{|l|c|c|c|c|c|}
\hline Constructs & $\begin{array}{c}\text { Precarious } \\
\text { Work (PW) }\end{array}$ & $\begin{array}{c}\text { Social } \\
\text { Dialogue } \\
\text { (SD) }\end{array}$ & $\begin{array}{c}\text { Satisfaction } \\
\text { with Life } \\
\text { Scale } \\
\text { (SWLS) }\end{array}$ & $\begin{array}{c}\text { Unacceptable } \\
\text { Work (UW) }\end{array}$ & $\begin{array}{c}\text { Working } \\
\text { Hours (WH) }\end{array}$ \\
\hline Precarious Work (PW) & ---- & $\mathbf{0 . 9 9 3}$ & 0.073 & 0.050 & 0.043 \\
\hline Social Dialogue (SD) & ---- & 1.000 & 2.174 & 1.993 & 1.993 \\
\hline Satisfaction with Life & ---- & ---- & 0.022 & 0.063 & $\mathbf{0 . 2 8 8}$ \\
\hline Scale (SWLS) & ---- & ---- & 2.681 & 1.993 & 1.993 \\
\hline Unacceptable Works & ---- & ---- & ---- & ---- & ---- \\
\hline (UW) & ---- & ---- & ---- & ---- & --- \\
\hline Working Hours (WH) & ---- & ---- & 0.055 & ---- & ---- \\
\hline
\end{tabular}




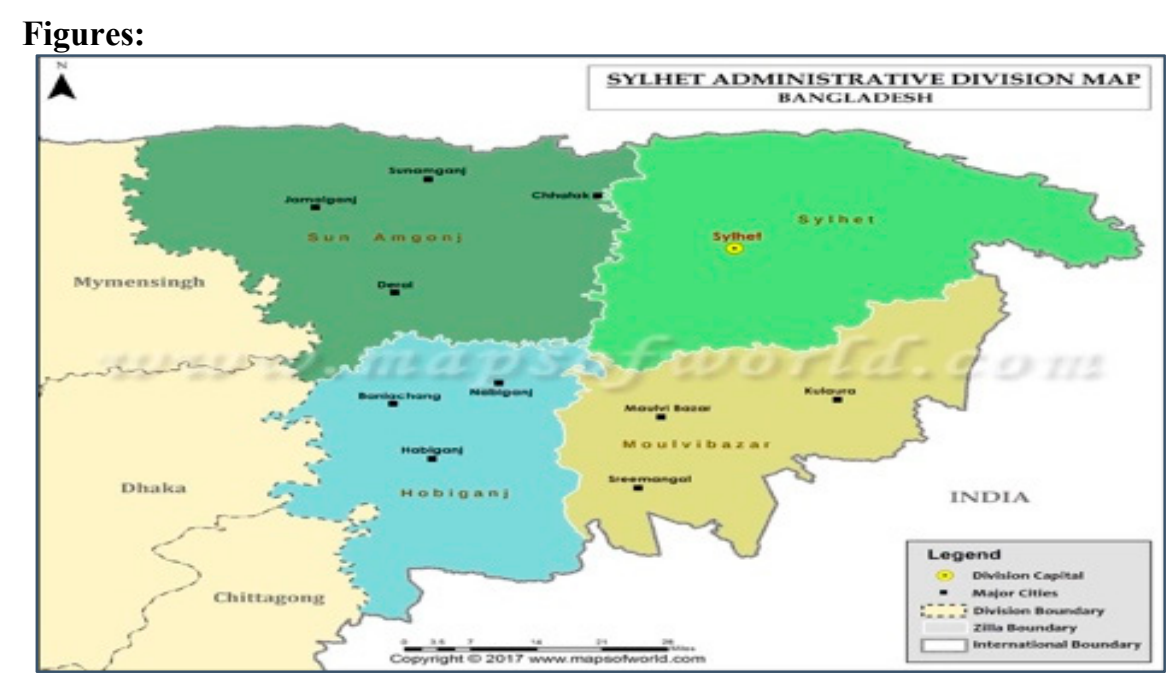

Figure 1: A reference map of the northeast region (Sylhet division) of Bangladesh (digirev.us)

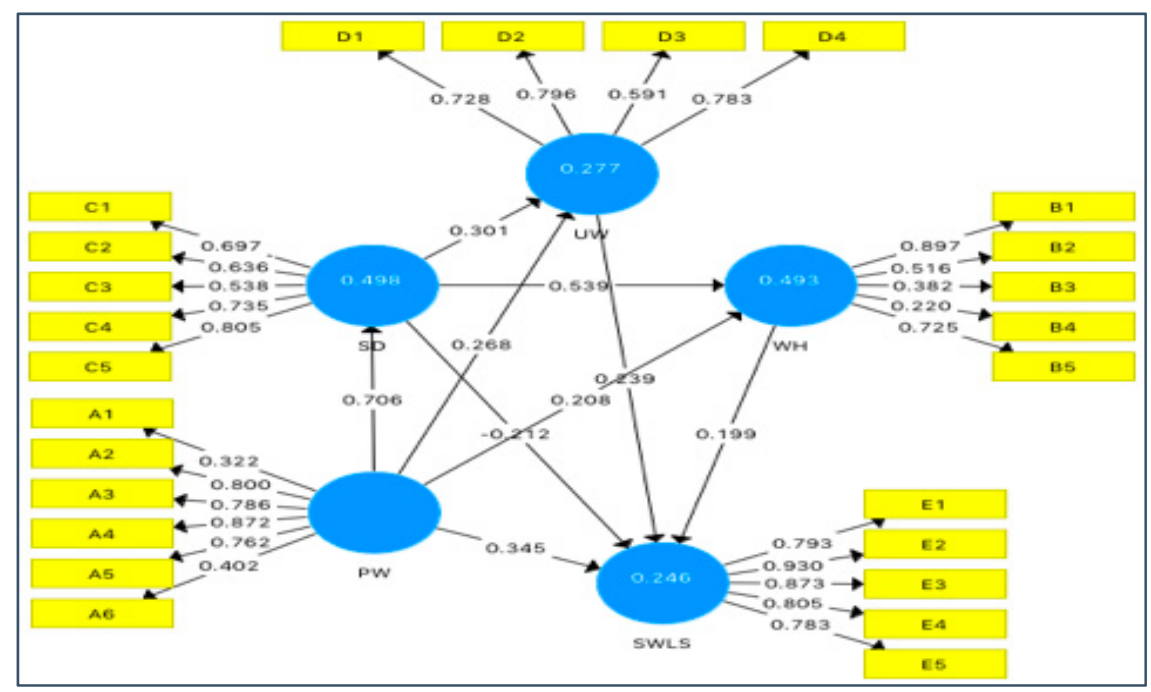

Figure 2: Path coefficients and R squares

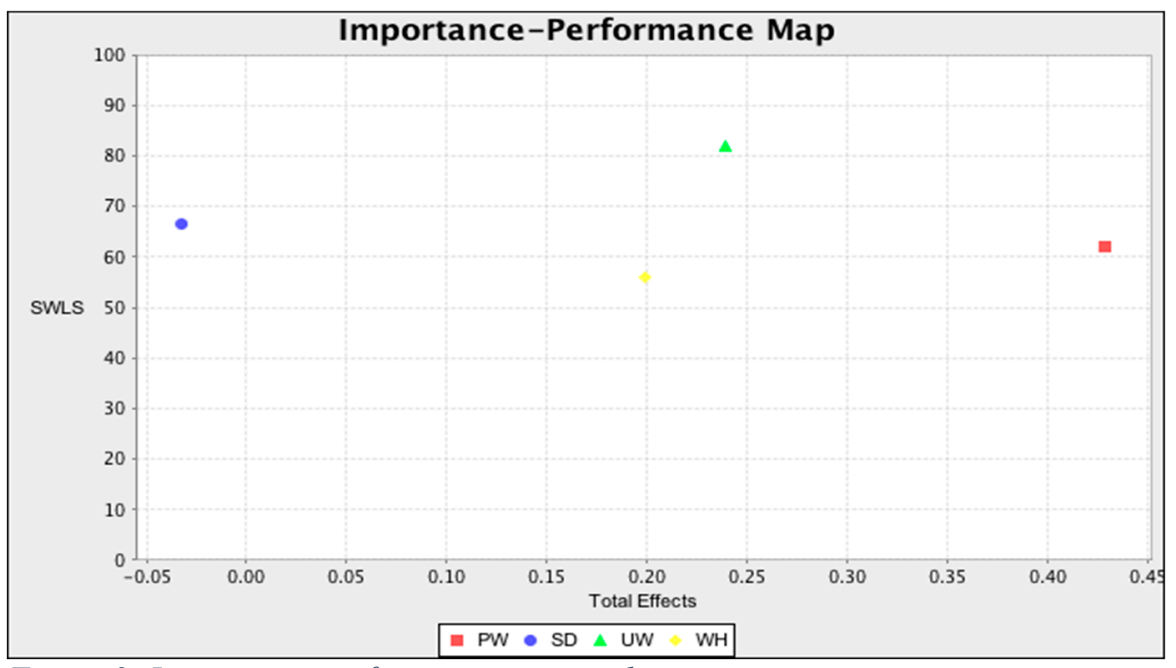

Figure 3: Importance performance map analysis 